\title{
Management and Molecular Diagnosis of Persistent Müllerian Duct Syndrome in Chinese Patients
}

\author{
Hongjuan Tian \\ Zhejiang University School of Medicine Children's Hospital https://orcid.org/0000-0002-1109-8547 \\ Dehua Wu \\ Zhejiang University School of Medicine Children's Hospital \\ Wei Ru \\ Zhejiang University School of Medicine Children's Hospital \\ Dingwen Wu \\ Zhejiang University School of Medicine Children's Hospital \\ Chang Tao \\ Zhejiang University School of Medicine Children's Hospital \\ Guangjie Chen \\ Zhejiang University School of Medicine Children's Hospital \\ Jinna Yuan \\ Zhejiang University School of Medicine Children's Hospital \\ Junfen Fu \\ Zhejiang University School of Medicine Children's Hospital \\ Daxing Tang ( $\square$ tangdx0206@zju.edu.cn) \\ Children's Hospital, Zhejiang University School of Medicine https://orcid.org/0000-0003-2103-4931
}

\section{Research}

Keywords: persistent Müllerian duct syndrome, AMH, AMHR2, disorders of sex development

Posted Date: April 27th, 2021

DOl: https://doi.org/10.21203/rs.3.rs-443766/v1

License: (c) (i) This work is licensed under a Creative Commons Attribution 4.0 International License. Read Full License 


\section{Abstract}

Background: To report the management and molecular findings of patients with persistent Müllerian duct syndrome (PMDS).

Materials and Methods: The hospital records of PMDS patients seen in our center between 2012 and 2020 were retrospectively reviewed. Exome sequencing and Sanger verification were performed for accurate diagnosis. We also reviewed reported clinical and molecular data on PMDS.

Results: A total of 12 PMDS patients with a median age of 13 months and a median follow-up time of 25 months were included in the study. Preoperative diagnoses were obtained on the basis of ultrasound (7/12) and exome sequencing (1/12). Twelve different $A M H$ variants in 9 patients $(2$

frameshift/nonsense, 1 deletion, 8 missense, 1 in-frame) and 6 different $A M H R 2$ variants in 3 patients ( 5 missense, 1 splicing) were identified. Not all patients with $A M H$ defects showed low serum AMH concentrations (2/9), but all patients with $A M H R 2$ defects showed elevated AMH levels (3/3). During surgery, an abnormal vas deferens was observed in half of the patients. Patients with orchidopexy with uterine preservation presented complications including irreducible cryptorchidism (2/8) and Müllerian remnant cysts (3/8). Patients with subtotal hysterectomy had complications of injury to the vas deferens (1/3) and hemorrhage $(1 / 3)$.

Conclusions: This is the first report involving a large Chinese population. The present study not only expands the variation spectrum but also provides new insights into the management of the uterus.

\section{Background}

Persistent Müllerian duct syndrome (PMDS, OMIM\# 261550) is a rare recessive disorder characterized by the persistence of Müllerian derivatives, uterus and tubes, in otherwise normally virilized males. ${ }^{1}$ The karyotype of individuals with PMDS is $46, \mathrm{XY}$, the urethra opens normally at the glans and the gonads are testes. PMDS has three main clinical presentations: bilateral cryptorchidism, unilateral cryptorchidism with inguinal hernia, and transverse testicular ectopia (TTE). ${ }^{2}$ The presence of Müllerian remnants (MRs) is usually discovered unexpectedly during orchidopexy or routine inguinal hernia repair. ${ }^{2}$ The diagnosis can be missed during the initial surgery, leading to reoperations. The uterus is usually an obstacle to testicular descent and at risk of malignant degeneration. ${ }^{2-5}$ However, removing the uterus almost unavoidably damages the vas deferens or the deferential artery. ${ }^{2}$ It is currently difficult to identify PMDS preoperatively and the debate continues about how to deal with the uterus.

Biallelic loss-of-function variants in two genes ( $A M H$ and $A M H R 2)$ have been identified in patients with PMDS. The $A M H$ gene is a $2.8 \mathrm{~kb}-$ long gene containing five exons located on chromosome 19p13.3, and its protein product is a glycoprotein dimer belonging to the TGF- $\beta$ family that acts via its specific receptor (AMHR2). The AMHR2 gene, located on 12q13, contains 11 exons and encodes a serine/threonine kinase belonging to the TGF- $\beta$-related protein family. To date, 85 different variants in $A M H$ and 84 variants in $A M H R 2$ have been identified. (Human Gene Mutation Database: http://www.hgmd.cf.ac.uk/). However, few variants have been reported in Chinese individuals with PMDS. ${ }^{6}$

In this report, we studied the management experiences and genetic findings of 12 patients with PMDS in China. On the basis of a literature review, we defined procedures for the diagnosis and treatment of PMDS.

\section{Materials And Methods}

\section{Patients}

The study included all patients with PMDS admitted to the Department of Urology at Children's Hospital Zhejiang University School of Medicine, from Jan 2012 to Dec 2020. The inclusion criteria were $\otimes$ normal male external genitalia, $\bigotimes$ a $46, X Y$ karyotype, and $\otimes$ the presence of MRs ascertained by surgical exploration. The exclusion criteria included $₫$ a lack of molecular diagnosis and $\nabla$ an absence of treatment or follow-up. Data on demographics, clinical presentations, molecular findings, AMH levels, surgical findings and outcomes were retrospectively reviewed. Approval of the ethical committee was previously obtained. Written informed consent was obtained from all participants in this study.

\section{Methods}

AMH levels were determined via the Immunotech AMH/MIS enzyme immunoassay (UniCel DXI800; Beckman Coulter, Fullerton, CA, USA). G-banding karyotyping was carried out using peripheral lymphocytes.

For targeted next-generation sequencing, genomic DNA was extracted from peripheral blood samples of patients using a QIAamp DNA Blood Mini Kit (Qiagen $\mathrm{GmbH}$, Hilden, Germany). Paired-end libraries were generated with the Agilent Sure Select Target Enrichment System and an XT Inherited Disease Panel containing 2742 genes (Agilent Technologies Inc., Santa Clara, CA, US) according to the manufacturer's instructions. Sequencing was performed on an Illumina HiSeq 2500 System (Illumina Inc., San Diego, CA, US). The analysis was carried out using an in-house pipeline adapted from BWA, GATK 4.0.0.0 and SAMtools 1.8. The identified variants were confirmed by Sanger sequencing in the patients and their parents. When a confirmed origin of the observed variants was lacking in the patients, their parents also underwent exome sequencing. AMH/AMHR2 copy numbers were determined through CapCNV analysis followed by the CNVkit protocol (https://cnvkit.readthedocs.io/en/stable/pipeline.html).

Multiple prediction tools such as ClinPred and REVEL were implemented to predict the possible impact of the variants. The pathogenicity of the variants was also classified according to the criteria recommended by the American College of Medical Genetics and Genomics/Association for Molecular Pathology (ACMG/AMP) 2015 guidelines ${ }^{7}$. 


\section{Results}

\section{Clinical Findings}

A total of 12 patients with a median age of 10 months (range, 2 to 49 months) were included in the study, which was conducted over 9 years (Table 1 ). None of the parents were consanguineous. Among the patients, 6 presented with unilateral cryptorchidism (50\%) (Fig. 1), 3 with bilateral cryptorchidism (25\%), and 3 with TTE (25\%). The diagnosis was carried out preoperatively by ultrasound in 7 patients and gene sequencing in 1 patient (Fig. 2 ). Notably, patients 1 and 2 were brothers, and patient 2 was diagnosed by exome sequencing because his brother had PMDS. 
Table 1

\begin{tabular}{|c|c|c|c|c|c|c|c|c|c|c|}
\hline Patient & $\begin{array}{l}\text { Age } \\
\text { (M) }\end{array}$ & Presentation & $\begin{array}{l}\text { How to } \\
\text { diagnosis it }\end{array}$ & $\begin{array}{l}\text { Preoperatively } \\
\text { diagnosed }\end{array}$ & $\begin{array}{l}\text { AMH } \\
\text { (ng/ml) }\end{array}$ & Gene & Mutation & a.a. change & Protein & $\begin{array}{l}\text { Paren } \\
\text { Valida }\end{array}$ \\
\hline \multirow[t]{2}{*}{1} & \multirow[t]{2}{*}{8} & \multirow[t]{2}{*}{$\begin{array}{l}\text { Left } \\
\text { cryptorchidism, } \\
\text { Bilateral hernia }\end{array}$} & \multirow{2}{*}{$\begin{array}{l}\text { Müllerian } \\
\text { structurs noted } \\
\text { during surgery } \\
\text { for hernia }\end{array}$} & \multirow[t]{2}{*}{ No } & \multirow[t]{2}{*}{5.18} & \multirow[t]{2}{*}{$\mathrm{AMH}$} & c.1522_1524dupGTG & p.V508dup & in-frame & $\mathrm{F}$ \\
\hline & & & & & & & c. $1637 \mathrm{C}>\mathrm{A}$ & p.A546E & missense & $M$ \\
\hline \multirow[t]{2}{*}{2} & \multirow[t]{2}{*}{49} & \multirow{2}{*}{$\begin{array}{l}\text { Left } \\
\text { orchiatrophy, } \\
\text { Right hernia }\end{array}$} & \multirow{2}{*}{$\begin{array}{l}\text { Exon } \\
\text { sequencing } \\
\text { was positive } \\
\text { because his } \\
\text { brother was } \\
\text { patient } 1\end{array}$} & \multirow[t]{2}{*}{ No } & \multirow[t]{2}{*}{$<0.06$} & \multirow[t]{2}{*}{$\mathrm{AMH}$} & c.1522_1524dupGTG & p.V508dup & in-frame & $\mathrm{F}$ \\
\hline & & & & & & & c. $1637 \mathrm{C}>\mathrm{A}$ & p.A546E & missense & M \\
\hline \multirow[t]{2}{*}{3} & \multirow[t]{2}{*}{10} & \multirow{2}{*}{$\begin{array}{l}\text { Bilateral } \\
\text { cryptorchidism, } \\
\text { left hernia }\end{array}$} & \multirow{2}{*}{$\begin{array}{l}\text { Both testes } \\
\text { detected at left } \\
\text { groin by } \\
\text { ultrasound }\end{array}$} & \multirow[t]{2}{*}{ Yes } & \multirow[t]{2}{*}{80.88} & \multirow[t]{2}{*}{$\mathrm{AMH}$} & c. $1352 \mathrm{G}>\mathrm{A}$ & p.R451H & missense & $\mathrm{F}$ \\
\hline & & & & & & & c. $301 \mathrm{G}>\mathrm{A}$ & p.G101R & missense & M \\
\hline \multirow[t]{2}{*}{4} & \multirow[t]{2}{*}{0.6} & \multirow{2}{*}{$\begin{array}{l}\text { Left } \\
\text { cryptorchidism, } \\
\text { Right hernia, } \\
\text { TTE }\end{array}$} & \multirow{2}{*}{$\begin{array}{l}\text { Both testes } \\
\text { detected at } \\
\text { right scrotum } \\
\text { by PE and } \\
\text { ultrasound }\end{array}$} & \multirow[t]{2}{*}{ Yes } & \multirow[t]{2}{*}{0.91} & \multirow[t]{2}{*}{$\mathrm{AMH}$} & c. $1604 \mathrm{~T}>\mathrm{C}$ & p.L535P & missense & $\mathrm{F}$ \\
\hline & & & & & & & c. $584 \mathrm{~A}>\mathrm{G}$ & p.Y195C & missense & M \\
\hline \multirow[t]{2}{*}{5} & \multirow[t]{2}{*}{16} & \multirow{2}{*}{$\begin{array}{l}\text { Left } \\
\text { cryptorchidism, } \\
\text { Right hernia }\end{array}$} & Müllerian & No & $<0.06$ & $\mathrm{AMH}$ & c. $1165 G>T$ & p.E389X & nonsense & $\mathrm{F}$ \\
\hline & & & for hernia & & & & - & - & deletion & M \\
\hline 6 & 2 & $\begin{array}{l}\text { Bilateral } \\
\text { cryptorchidism, }\end{array}$ & $\begin{array}{l}\text { Both testes } \\
\text { detected at }\end{array}$ & Yes & $<0.06$ & $\mathrm{AMH}$ & c. $707 \mathrm{G}>\mathrm{A}$ & p.G236D & missense & $\mathrm{F}$ \\
\hline & & Bilateral hernia & $\begin{array}{l}\text { right groin by } \\
\text { ultrasound }\end{array}$ & & & & c. $301 \mathrm{G}>\mathrm{A}$ & p.G101R & missense & M \\
\hline 7 & 2 & Bilateral & Gene & Yes & 0.05 & $\mathrm{AMH}$ & c. $1165 \mathrm{G}>\mathrm{T}$ & p.E389X & nonsense & $\mathrm{F}$ \\
\hline & & & was pustive & & & & c. $1165 \mathrm{G}>\mathrm{T}$ & p.E389X & nonsense & M \\
\hline 8 & 10 & Right & Both testes & Yes & 8.01 & $\mathrm{AMH}$ & c. $992 \mathrm{C}>\mathrm{T}$ & p.S331L & missense & $\mathrm{F}$ \\
\hline & & TTE & by ultrasound & & & & c. $301 \mathrm{G}>\mathrm{A}$ & p.G101R & missense & M \\
\hline 9 & 11 & $\begin{array}{l}\text { Left } \\
\text { cryptorchidism }\end{array}$ & $\begin{array}{l}\text { Müllerian } \\
\text { structurs noted }\end{array}$ & No & $\begin{array}{l}> \\
168.57\end{array}$ & $\mathrm{AMH}$ & c. $1447 \mathrm{~T}>\mathrm{C}$ & p.Y483H & missense & $\mathrm{F}$ \\
\hline & & & $\begin{array}{l}\text { for } \\
\text { cryptorchidism. }\end{array}$ & & & & c.102dupC & p.S35Qfs*46 & frameshift & M \\
\hline 10 & 2 & Left & Left testis & Yes & $>24.5$ & AMHR2 & c. $356 \mathrm{~A}>\mathrm{G}$ & p.N119s & missense & $\mathrm{F}$ \\
\hline & & Right hernia & $\begin{array}{l}\text { groin by } \\
\text { ultrasound }\end{array}$ & & & & c. $733 \mathrm{G}>\mathrm{A}$ & p.A245T & missense & $M$ \\
\hline 11 & 12 & $\begin{array}{l}\text { Left } \\
\text { cryptorchidism }\end{array}$ & Both testes & Yes & 214.67 & AMHR2 & c.706T >A & p.S236T & missense & $\mathrm{F}$ \\
\hline & & & $\begin{array}{l}\text { right scrotum } \\
\text { by ultrasound }\end{array}$ & & & & c. $160 \mathrm{C}>\mathrm{T}$ & p.R54C & missense & M \\
\hline 12 & 2 & $\begin{array}{l}\text { Left } \\
\text { cryptorchidism, }\end{array}$ & $\begin{array}{l}\text { Left testis } \\
\text { detected at }\end{array}$ & Yes & 117.62 & AMHR2 & c. $337 \mathrm{~A}>\mathrm{C}$ & p.T113P & missense & M \\
\hline & & & & & & & c. $1288+23 \mathrm{C}>\mathrm{A}$ & - & missense & $\mathrm{F}$ \\
\hline & & Right hernia & $\begin{array}{l}\text { right internal } \\
\text { ring by } \\
\text { ultrasound }\end{array}$ & & & & & & & \\
\hline
\end{tabular}

$M$, month. F, paternal inheritance. $M$, maternal inheritance. F/M, inherited respectively from parents. P, pathogenic. LP, likely pathogenic. VUS, uncertain signifi 


\section{Molecular Findings And Amh Levels}

We identified 12 different $A M H$ variants in 9 patients ( 2 frameshift/nonsense, 1 deletion, 8 missense, 1 in-frame) and 6 different $A M H R 2$ variants in 3 patients (5 missense, 1 splicing) (Fig. 3) (Table S1). The variants in AMH and AMHR2 occurred in the compound heterozygous form in all patients except for patient 7 , who harbored a homozygous variant in $A M H$. The same nonsense variant (p.E389X) in $A M H$ occurred in patient 5 and patient 7 , while the same missense variant (p.G101R) in patient 3, 6 and 8 . The number of detected / independent variants in the N-terminal region of $A M H$ was $8 / 5$, while that in the TGF-beta-like domain was $3 / 3$. Three missense variants occurred in the activin type I and II receptor domain of $A M H R 2$, and two occurred in the Protein Kinases catalytic domain. Of the 12 identified variants in $A M H, 8$ are novel, and 4 missense variants have been reported previously. According to the ACMG 2015 criteria, 7 variants were classified as "pathogenic", or "likely pathogenic", and 5 of them were novel. Three detected variants occurred in Activin types I and II receptor domain of AMHR2, and two in Protein Kinases catalytic domain. Of the 6 identified variants in AMHR2, 5 are novel and "VUS", and the other missense variant is classified as "LP".

All but two patients with $A M H$ gene defects showed low or undetectable serum AMH concentrations. The two exceptions were patient 3 (80.88 $\mathrm{ng} / \mathrm{mL})$ and patient 9 (> $168.57 \mathrm{ng} / \mathrm{mL})$. All patients with AMHR2 gene defects presented elevated AMH levels.

\section{Intervention And Follow-up}

All patients underwent laparoscopic exploration and bilateral orchidopexy. Eight patients preserved the uterus. Three patients underwent subtotal hysterectomy, which was accompanied by complications of injury to the vas deferens in one patient and hemorrhage in another patient. The uterus in the last patient could not be detected by laparoscopy or imaging. During surgery, the vas deferens was observed to be blind and dissociated from the testes in six patients (50\%). For histopathology, testicular biopsies were performed in 6 patients, and the examination of sections confirmed testicular microlithiasis (TM) in half of the patients, while the others presented normal infantile testes. Patient 7 underwent retrograde urethrography showing a long narrow prostatic utricle (Fig. 4A, B)

All patients were followed up with a median follow-up time of 31 months (range, 7 to 95 months). We observed complications in six patients. One patient suffered bilateral hernia recurrence, which was repaired during reoperation. Five of eight patients whose uterus was retained presented complications of irreducible cryptorchidism (2/8) and MR cysts (3/8). One patient with irreducible cryptorchidism was followed-up without further intervention; the other underwent two additional surgeries to repair the normal-side testis. MR cysts occurred in the scrotum, groin or pelvis. The size of the cyst in patient 4 was small and stable $(2.3 \mathrm{~cm} \subseteq 0.8 \mathrm{~cm})$, and the size in patient 9 was enlarged at one time point $(6.3 \mathrm{~cm} \subseteq 4.0 \mathrm{~cm})$ but has now been reduced $(1.5 \mathrm{~cm} \subseteq 1.1 \mathrm{~cm})$. Patient 10 exhibited a progressively enlarged cyst $(6.2 \mathrm{~cm} \times 1.6 \mathrm{~cm}) 25$ months after the operation and continued to undergo follow-up without further intervention (Fig. 4C, D).

\section{Description Of The Variant Spectrum Of The Literature}

Based on a review of 157 cases in 2017, ${ }^{8}$ nine published peer-reviewed articles were identified. Adding to our patients in China, there were 93 families with 78 different variants in $A M H$ (Table S2) and 94 families with 80 different variants in AMHR2 (Table S3). 6,8-16 The relationship between the phenotypes and genotype of all patients was analyzed statistically (Fig. 4). There was no significant difference in anatomy between patients with either $A M H$ or $A M H R 2$ variants. A total of $56.6 \%$ of the patients presented with bilateral cryptorchidism, $20.8 \%$ with unilateral cryptorchidism, and $22.5 \%$ with TTE. Variants in $A M H$ and AMHR2 were detected in $87.9 \%$ of all cases. Meanwhile, all TTE with PMDS has possible causative variants.

Variants occur along the whole length of $A M H$ and $A M H R 2$ (Fig. 2A). The large N-terminal fragment is hit 70 times. The TGF-beta like domain in C-terminus is hit 26 times. The variant rate in the N-terminal region was nearly 2.5 times that of the TGF-beta-like domain. The Activin types I and II receptor domain in AMHR2 is an extracellular domain, and are hit 8 times. The Protein Kinases catalytic domain in AMHR2 is located in the intracellular domain and is hit 37 times and 4 times more than the receptor domain.

\section{Discussion}

PMDS is one of the rarest causes of disorders of sex development (DSD) with clinical and genetic heterogeneity and is characterized by the presence of a bicornuate uterus, fallopian tubes, and the upper third of the vagina in normally masculinized $46, \mathrm{XY}$ subjects. ${ }^{1}$ The incidence has not been accurately determined. Since its initial description, the details of more than 250 cases have been published, and variants in $A M H$ and $A M H R 2$ have been identified in these patients. Thus far, few studies from China have reported the variant spectrum and management experiences of PMDS patients. In the current study, we report the clinical experiences and genetic findings of 12 new patients from China.

In our literature review, $56.6 \%$ of the included patients presented with bilateral cryptorchidism, $20.8 \%$ with unilateral cryptorchidism, known as hernia uteri inguinalis, and $22.5 \%$ with TTE (Figure S1). The data were updated and included newly reported patients and our Chinese patients ${ }^{2}$. However, in the current study, unilateral cryptorchidism present in more than half of the patients, was the most common phenotype. We also found that the position of the testis was flexible and was always reset during laparoscopic exploration, although it was preoperatively detected on the contralateral side of the body (mostly in the groin) by ultrasound (Table 1). It is easy to confuse TTE with unilateral cryptorchidism, and it is possible that there is no need to distinguish them. Moreover, the high flexibility of the testes due to the abnormal mobility of the uterus facilitates their torsion and may lead to uni- or bilateral testicular degeneration. ${ }^{17}$ The testis of patient 2 was ascertained to be atrophied. 
In children, PMDS is usually a surprising finding made during corrective surgery for inguinal hernia or cryptorchidism. Testicular histology is generally

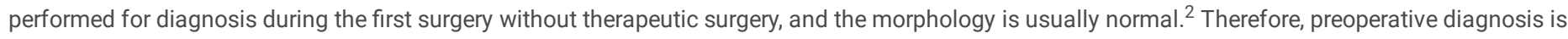
critical and can help to avoid unnecessary testicular biopsy and reoperations. Unilateral or bilateral cryptorchidism is not particularly evocative, although unilateral cryptorchidism with contralateral hernia, particularly TTE, should evoke suspicion. In the present study, the diagnosis was made preoperatively in more than half of the patients. Seven of these patients underwent ultrasound, and one patient underwent gene sequencing. If physical examination and ultrasound show any sign of a testis crossing the body midline, PMDS should be considered. Moreover, preoperative gene sequencing can contribute to an accurate diagnosis when a damaging variant of $A M H$ or $A M H R 2$ is detected.

In our literature review, variants of $A M H$ and $A M H R 2$ were reported in $87.9 \%$ of all patients and were approximately equally distributed among the genes coding $A M H$ and its type II receptor, $A M H R 2$. Statistics indicated that $A M H$ presented 78 different variants in 93 families, and 80 different alleles of $A M H R 2$ were discovered in 94 families. In our Chinese patients, mutational analyses revealed possible causative variants in all patients. $A M H$ variants occurred more frequently than $A M H R 2$ variants, consistent with a previous report. ${ }^{2}$ Variants are known to occur along the entire length of $A M H$, although exons 3 and 4 are very rarely involved (Fig. 2A). The short C-terminal fragment is a TGF-beta like domain with biological activity. The large $\mathrm{N}$-terminal region is not thought to be essential for activity, but exerts the ability to stabilize the C-terminus, ${ }^{18}$ and shows nearly 2.5 times the hit of the C-terminus (Fig. $2 \mathrm{~A}$ ). In our study, twelve variants, including eight new variants, were identified in $A M H$. The c.301G > A (p.G101R) and c. 1165G > T (p.E389X) were recurrent in three and two unrelated families respectively. c.301G > A (p.G101R) has been previously described in four families, while c.1165G > T (p.E389X) has been reported in two families. c. $1637 \mathrm{C}>\mathrm{A}$ (p.A546E) was also previously detected in one family. AMHR2 encodes a membrane protein and has 11 exons, which are all affected by variants (Fig. 2B). Only two hits were observed in the transmembrane domain. The protein kinase catalytic domain was more conserved and showed nearly 5 times more hits than the activin types I and II receptor domains. In our Chinese patients, six variants in the AMHR2 gene were found, including five new variants of "uncertain significance (VUS)". c.160C > T (p.R54C) was previously described in one family. ${ }^{19}$ Functional studies have not been reported, so further studies are needed to investigate the harmfulness of these variants.

Normally, AMH concentrations are maintained at high levels during childhood and decrease at puberty ${ }^{20}$. Patients with $A M H$ gene defects show low AMH levels from birth, whereas patients with variants in $A M H R 2$ show elevated AMH levels, indicating insensitivity of the target tissues ${ }^{21}$. In contrast, patients 3 and 9 with variants in $A M H$ presented increased $A M H$ levels, indicating that the interactions between variants $p .(R 451 H)$ and $p$.(G101R) and between $p$. $\left(\mathrm{S} 35 \mathrm{Qfs} \mathrm{s}^{\star} \mathrm{6}\right)$ and $\mathrm{p} .(\mathrm{Y} 483 \mathrm{H})$ might affect hormone bioactivity and not the hormone secretion rate. ${ }^{22}$

The genotypes of $A M H$ and $A M H R 2$ are not related to the observed phenotypes ${ }^{2,23}$. The phenotype can differ within the same family and shows no relationship to the type of genetic defect involved. The anatomical abnormalities common to all patients with PMDS result from the failure of the gubernaculum to anchor the testes at the base of the scrotum. The abnormal mobility of the uterus with the testes facilitates their torsion and may lead to unior bilateral testicular degeneration ${ }^{17}$. In the current study, the left testis of patient 1 was located in the left groin, while the testis of his brother, patient 2 , was atrophied on the left side. Furthermore, neither laparoscopy nor imaging was able to detect Müllerian derivatives in patient 2, even though he harbored the same variants as his brother with PMDS (patient 1). This suggests highly variable penetrance of the abnormal alleles and/or the existence of other genetic or epigenetic modifiers of gene expression.

The management of PMDS consists of the correction of cryptorchidism to prevent testis degeneration and preserve fertility. ${ }^{2,24}$ Because of the high mobility of the uterus with the testes, bilateral orchidopexy is recommended, as we performed in the current study. The rate of testicular malignancy is up to $33 \%$ in PMDS patients older than 18 years, which is higher than the rate among general cryptorchidism cases. Close follow-up of the testes is necessary with age ${ }^{2}$.

There is no consensus regarding whether MRs should be excised in PMDS patients. Previous reports have advocated retaining MRs to prevent damage to the vas deferens, considering that MRs present no risk of malignancy ${ }^{25}$. In the current study, MRs were preserved in eight patients, but complications occurred in five patients. To our knowledge, this is the first study to report the emergence of MR cysts after MR preservation. The cysts were thought to be hydrocolpos caused by the accumulation of fluid due to congenital vaginal obstruction. In our experience, such cysts may decrease in size and remain stable, but long-term outcomes still need to be followed up. Irreducible cryptorchidism occurred in two patients following MR preservation, which may have been due to the mobilization of MRs.

Since 2002, three PMDS patients have been reported to have developed malignancy of MRs originating from the mucosa ${ }^{3-5}$. The preferred surgical procedure is to split the uterus in the middle, destroy the mucosal lining, and leave an intact pedicle of the myometrium. ${ }^{24,26,27}$ This not only releases the testes to the ideal position but also protects the integrity and vascularity of the vas deferens and reduces the chance of malignancy. In the current study, three patients underwent partial hysterectomy, but two of them experienced side effects. One presented the complication of hemorrhage, indicating that complete hemostasis should be noticed. The vas deferens is injured in TTE because it is enclosed in MRs, so surgeons need to improve their surgical techniques and perform dissection carefully. In addition to malignant degeneration, retained MRs are known to cause hematuria, recurrent UTI, stones and voiding disturbances ${ }^{27,28}$, but these conditions were not noticed in our series.

Infertility is another problem observed in PMDS patients. The possible causes include congenital malformations of excretory ducts, long-term cryptorchidism, and damage to the testicular blood supply or the vas deferens during hysterectomy. In the present study, the incidence of vas deferens malformation was high, occurring in half of the patients. We also noted a high incidence of TM (25\%), which may contribute to another cause of infertility. ${ }^{29}$

Follow-up is extremely important for these patients, especially the monitoring of malignancies of the testes and uterus, with concern for their fertility. Close follow-up of all of our patients continues in our clinic. 


\section{Perspectives and Significance}

We report 12 new Chinese PMDS patients with 13 novel possible causative variants in the $A M H$ and $A M H R 2$ genes. Bilateral orchidopexy with destruction of the uterine mucosa may be the optimum surgical procedure for PMDS.

\section{Abbreviations}

PMDS persistent Müllerian duct syndrome

TTE transverse testicular ectopia

MRs Müllerian remnants

TM testicular microlithiasis

ACMG American College of Medical Genetics and Genomics

AMP Association for Molecular Pathology

DSD disorders of sex development

\section{Declarations}

\section{Ethics approval and consent to participate}

The experimental protocol was established approved by the Human Ethics Committee of Children's Hospital Zhejiang University School of Medicine. Written informed consent was obtained from all participants in this study.

\section{Consent for publication}

Not applicable.

\section{Availability of data and materials}

All data generated or analysed during this study are included in this published article.

\section{Competing interests}

The authors declare that they have no competing interests.

\section{Funding}

This study was supported by National Key R\&D Program of China (Grant No. 2018YFC1002700).

\section{Authors' contributions}

H.T. and D.T. conceived and designed this study. D.T. and J.F. supervised this study. H.T. and D.W. wrote the manuscript. H.T. and C.T. extracted clinical data. D.W. analyzed the genetic variants. W.R. and J.Y. performed statistical analysis of results with assistance and/or inputs from other authors. C.T. and G.C. provided necessary study supports. All authors read and approved the final manuscript.

\section{Acknowledgements}

The authors thank Jian Wang (Shanghai Children's Medical Center, Shanghai Jiaotong University School of Medicine for the consultation on molecular knowledge, Rui Xiao (Boisan Biotechnology Co., Ltd) for the guidance on writing, and Shujie Zhang (Central South University) for the consultation on chart drawing

\section{References}

1. Knebelmann B, Boussin L, Guerrier D, et al. Anti-Müllerian hormone Bruxelles: a nonsense mutation associated with the persistent Müllerian duct syndrome. Proc Natl Acad Sci U S A. 1991;88(9):3767-71.

2. Picard JY, Josso N. Persistent Müllerian duct syndrome: an update. Reprod Fertil Dev. 2019;31(7):1240-5.

3. Shinmura Y, Yokoi T, Tsutsui Y. A case of clear cell adenocarcinoma of the müllerian duct in persistent müllerian duct syndrome: the first reported case. American Journal of Surgical Pathology. 2002;26(9):1231-4.

4. Romero FR, Fucs M, Castro MG, Garcia CR, Fernandes Rde C, Perez MD. Adenocarcinoma of persistent müllerian duct remnants: case report and differential diagnosis. Urology. 2005;66(1):194-5.

5. Thiel DD, Erhard MJ. Uterine adenosarcoma in a boy with persistent müllerian duct syndrome: first reported case. J Pediatr Surg. 2005;40(9):e29-31. 
6. Xu Y, Wang Y, Li N, et al. New insights from unbiased panel and whole-exome sequencing in a large Chinese cohort with disorders of sex development. Eur J Endocrinol. 2019;181(3):311-23.

7. Richards S, Aziz N, Bale S, et al. Standards and guidelines for the interpretation of sequence variants: a joint consensus recommendation of the American College of Medical Genetics and Genomics and the Association for Molecular Pathology. Genet Med. 2015;17(5):405-24.

8. Picard JY, Cate RL, Racine C, Josso N. The Persistent Müllerian Duct Syndrome: An Update Based Upon a Personal Experience of 157 Cases. Sexual Development. 2017;11(3):109-25.

9. Ren X, Wu D, Gong C. Persistent Müllerian duct syndrome: A case report and review. Exp Ther Med. 2017;14(6):5779-84.

10. Hughes LA, McKay-Bounford K, Webb EA, et al. Next generation sequencing (NGS) to improve the diagnosis and management of patients with disorders of sex development (DSD). Endocr Connect. 2019;8(2):100-10.

11. Fernández-Cancio M, Viswanath N, Puzhankara R, et al. A Novel Homozygous AMRH2 Gene Mutation in a Patient with Persistent Müllerian Duct Syndrome. Sex Dev. 2019;13(2):87-91.

12. Acero MG, Moreno 0 , Gutiérrez A, et al. Novel homozygous mutation in a colombian patient with persistent müllerian duct syndrome: expanded phenotype. Int Braz J Urol. 2019;45(5):1064-70.

13. Tosca L, Giltay JC, Bouvattier C, et al. Persistent Müllerian duct syndrome due to anti-Müllerian hormone receptor 2 microdeletions: a diagnostic challenge. Hum Reprod. 2020;35(4):999-1003.

14. Unal E, Karakaya AA, Beştaş A, et al. Identification of four novel variant in the AMHR2 gene in six unrelated Turkish families. J Endocrinol Invest. 2020.

15. Altincik A, Karaca F, Onay H. Persistent Müllerian duct syndrome: A novel mutation in the Anti-Müllerian Hormone gene. Hormones (Athens). 2017;16(2):205-8.

16. Nixon R, Cerqueira V, Kyriakou A, et al. Prevalence of endocrine and genetic abnormalities in boys evaluated systematically for a disorder of sex development. Hum Reprod. 2017;32(10):2130-7.

17. Imbeaud S, Rey R, Berta P, et al. Testicular degeneration in three patients with the persistent müllerian duct syndrome. Eur J Pediatr. 1995;154(3):187-90.

18. di Clemente N, Jamin SP, Lugovskoy A, et al. Processing of anti-mullerian hormone regulates receptor activation by a mechanism distinct from TGF-beta. Mol Endocrinol. 2010;24(11):2193-206.

19. Imbeaud S, Belville C, Messika-Zeitoun L, et al. A 27 base-pair deletion of the anti-müllerian type II receptor gene is the most common cause of the persistent müllerian duct syndrome. Hum Mol Genet. 1996;5(9):1269-77.

20. Aksglaede L, Sørensen K, Boas M, et al. Changes in anti-Müllerian hormone (AMH) throughout the life span: a population-based study of 1027 healthy males from birth (cord blood) to the age of 69 years. J Clin Endocrinol Metab. 2010;95(12):5357-64.

21. Rey RA, Codner E, Iñíguez G, et al. Low risk of impaired testicular Sertoli and Leydig cell functions in boys with isolated hypospadias. $J$ Clin Endocrinol Metab. 2005;90(11):6035-40.

22. Belville $\mathrm{C}$, Van Vlijmen $\mathrm{H}$, Ehrenfels $\mathrm{C}$, et al. Mutations of the anti-mullerian hormone gene in patients with persistent mullerian duct syndrome: biosynthesis, secretion, and processing of the abnormal proteins and analysis using a three-dimensional model. Mol Endocrinol. 2004;18(3):708-21.

23. Abduljabbar M, Taheini K, Picard JY, Cate RL, Josso N. Mutations of the AMH type II receptor in two extended families with persistent Müllerian duct syndrome: lack of phenotype/genotype correlation. Horm Res Paediatr. 2012;77(5):291-7.

24. Sancar S, Özçakır E, Kaya M. Management of the patients with persistent Müllerian duct syndrome: Is the ultimate goal testicular descent? Turk J Urol. 2018;44(2):166-71.

25. Vandersteen DR, Chaumeton AK, Ireland K, Tank ES. Surgical management of persistent müllerian duct syndrome. Urology. 1997;49(6):941-5.

26. Parelkar SV, Gupta RK, Oak S, et al. Laparoscopic management of persistent mullerian duct syndrome. Pediatric Surgery International. 2009;19(9):533-6.

27. Manjunath BG, Shenoy VG, Raj P. Persistent müllerian duct syndrome: How to deal with the müllerian duct remnants - a review. Indian J Surg. 2010;72(1):16-9.

28. Gricourt S, Treton D, Renard-Pennat R, et al. Novel anti-mullerian hormone mutation revealed by haematospermia in a 60-year-old patient. Clin Endocrinol (Oxf). 2011;74(3):404-5.

29. D'Andrea S, Martorella A, Castellini C, et al. Clinical and seminal parameters associated with testicular microlithiasis and its severity in males from infertile couples. Hum Reprod. 2021.

\section{Figures}



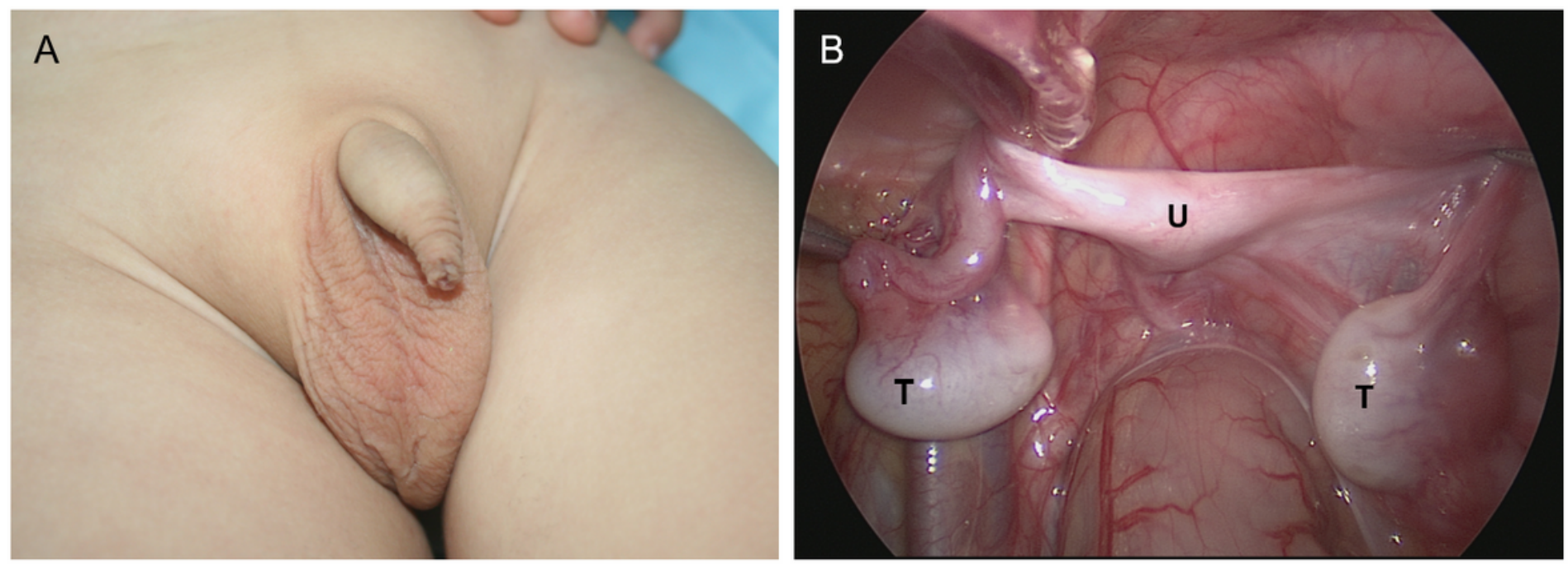

\section{Figure 1}

Normally virilized external genitalia (A) and unexpected M\&uuml;llerian remnants in the pelvic cavity (B). A. The length and size of the penis is normal-for-age and its urethra opens at the glans. The scrotum is empty. $B$. There is a uterus $(U)$ between two intra-abdominal testes $(T)$.

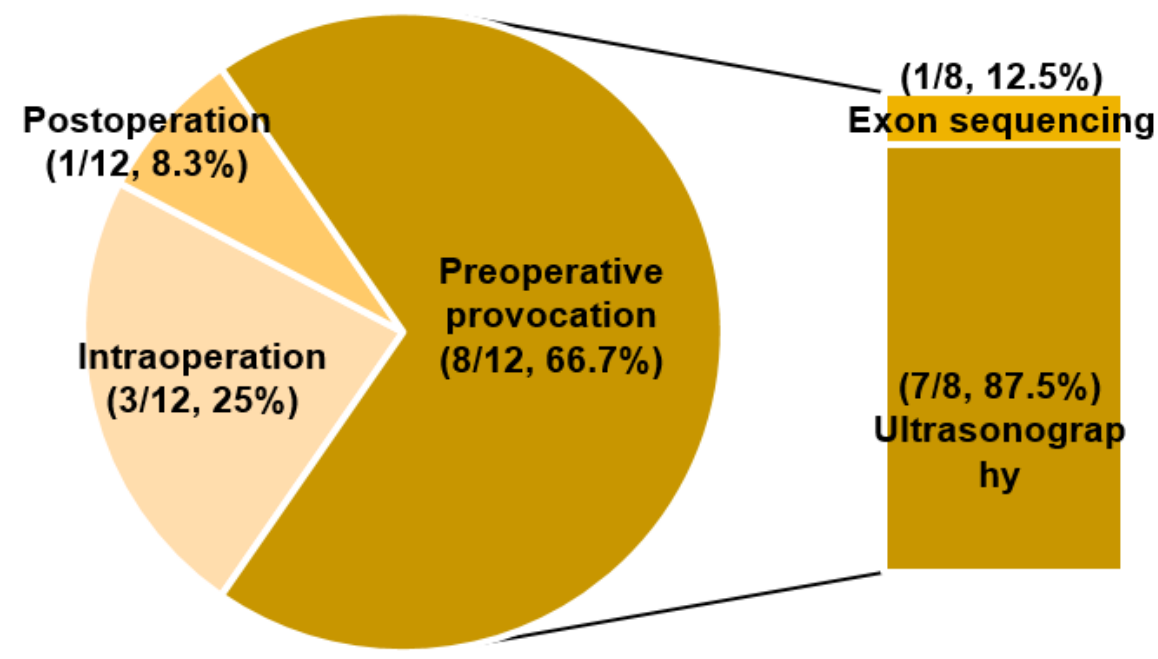

Figure 2

Timing of PMDS evocation and detection methods. A preoperative diagnosis was made in $66.7 \%(8 / 12)$ of cases, including 7 cases in which the testes crossed the body midline according to ultrasonography and 1 case diagnosed by exon sequencing. The postoperative diagnosis obtained by exon sequencing was unilateral testis. The last three cases were identified due to the presence of the uterus during corrective surgery for hernia or cryptorchidism. 

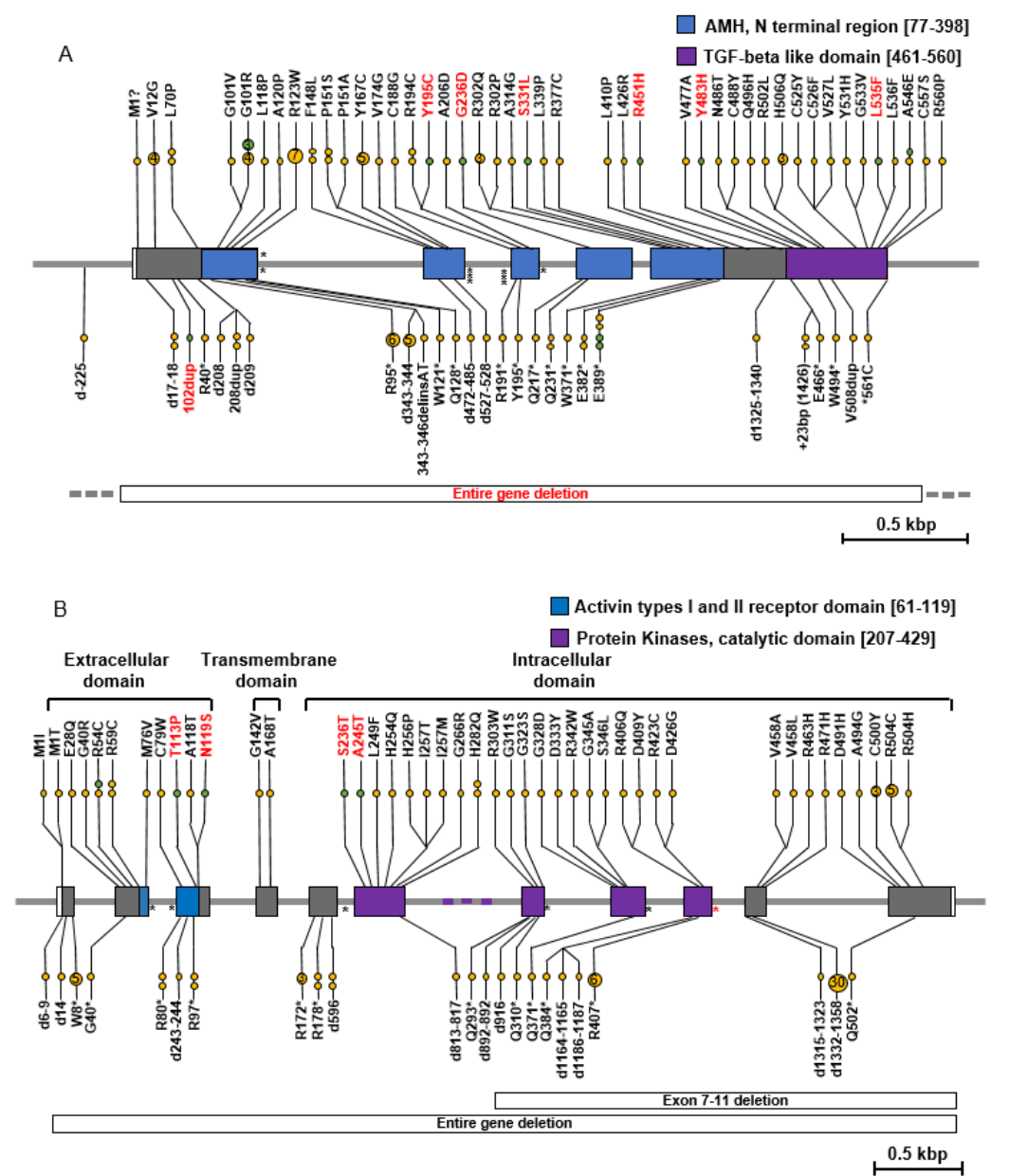

\section{Figure 3}

Summary of reported variants and novel variants in the gene (A) and gene (B). Green dots represent variants found in the present study; yellow dots represent variants previously reported in the literature. Each point represents one affected family. The number in the circle represents the times of reports. Novel variants are indicated in red. Missense variants are indicated on the top, and others are indicated on the bottom. Intron variants are indicated with (*). Variants in each domain cluster together.
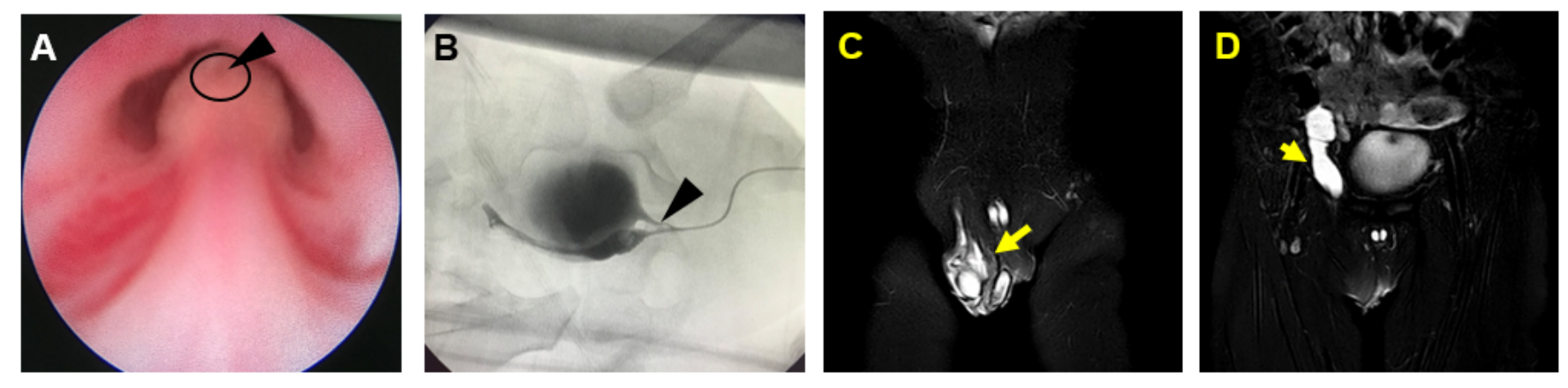

\section{Figure 4}

Images of M\&uuml;Ilerian remnants. A. Posterior urethral cystoscopy (patient 7). Cystoscopy demonstrated the verumontanum to be in a normal location with an edematous slit-like opening in its center (cursor). B. Retrograde urethrography (patient 7). The 3F catheter was inserted into the opening, which was long and narrow in the oblique coronal plane in retrograde urethrography. The cursor points to the confluence of the vagina and urethra. C. and D. Pelvic MRI (patient 10). This T2 coronal view demonstrates that the M\&uuml;llerian remnants (yellow arrow) extend from the scrotum along the groin and extend within the pelvic cavity on the normal side. The area measured $6.2 \mathrm{~cm} \&$ sube; $1.6 \mathrm{~cm}$. 


\section{Supplementary Files}

This is a list of supplementary files associated with this preprint. Click to download.

- FigureS1.pptx

- Tables1.docx

- Tables2.xlsx

- Tables3.xlsx 